\section{Contaminación del agua y calidad de vida}

\section{Argáiz, Agustín Loría}

Médico oftalmólogo. (UNAM, APEC); Maestría en Bioética. (ULIA); Maestría en Estudios Humanísticos. (TEC. De Monterrey); Hospital Cemain. Tampico. Presidente del Comité de Bioética; Instituto Tecnológico y de Estudios Superiores de Monterrey, Campus Tampico. Profesor de Ética. E-mail dr_loria@hotmail.com

PALAVRAS-CHAVE: Contaminación del Agua. Medio ambiente. Análisis hermenéutico.

Introducción: Al contaminar el agua, corremos el riesgo de beberla dañando nuestra salud y la de los demás seres vivos. Sería ideal "manejar el uso de recursos renovables como el agua, la tierra, los productos forestales y la vida marina, de manera de no exceder las posibilidades de regeneración y protejer la salud de los ecosistemas" (Carta de la Tierra). Método:La investigación, derivada del texto de Boff: "Que se contaminen las aguas potables", a la que se hará una interpretación hermenéutica de tipo analógico y simbólico, que consistirá en revisar las REFERÊNCIAS de los últimos años, con el fin de contrastar la realidad local con la del texto de Boff, en cuanto a contaminación del agua. Para ello se relacionarán símbolo y analogía, interpretando el texto de Boff; y a través de los resultados de la investigación de la zona de Tampico, aplicarlos en ambos escenarios. Desarrollo: El símbolo, parte esencial de la condición humana y a lo que el hombre se aferra para estar en la realidad; donde mejor se manifiesta el animal racional como hermeneuta, porque es donde más necesita la interpretación. En este entrecruce del hombre con lo simbólico se da la presencia de Hermes, quien se aparecía en los cruces de caminos, de manera que el símbolo funge como mediador y unión de extremos, en la encrucijada lingüística y lo ontológica.Se califica el agua como potable si cumple 41 parámetros estipulados en la norma. Las descargas de aguas residuales, que se vierten directamente a sistemas acuáticos y el proceso de deterioro de las cuencas hidrográficas, han provocado que los cuerpos de agua de la región se encuentren deteriorándose aceleradamente, lo que compromete su uso. Resultados: Es una de las cuencas más contaminadas de México, por la actividad industrial, petrolera, urbana y portuaria desarrollada en sus márgenes; por lo que más de sesenta variedades de peces y crustáceos se encuentran en peligro. CONCLUSIONES: Boff interpreta multívocamente la contaminación ambiental desde varios puntos de vista: político, económico y medioambiental. Apoyándose en la falta de justicia social y en que el derecho a trabajar el campo no sea crimen ecológico, buscando una reforma que respete y conserve las selvas y el agua. Para hacer una interpretación unívoca analógica, hay que valorar todos los factores que intervienen en la contaminación del agua, la que se puede potabilizar para consumo humano, de animales y para riego. En cuanto al símbolo el escrito de Boff, evidencia el desdén que el ser humano muestra por la vida y el futuro del planeta; nos lleva a darnos cuenta que un grado tal de contaminación como el que él denuncia y que comprobamos con este trabajo aterrizado en nuestra zona. Estamos contaminando nuestros cuerpos de agua, y es una descortesía para nuestros congéneres, las generaciones venideras, para la vida, para nosotros mismos, para las plantas y animales. Contaminación símbolo y signo de nuestra falta de respeto a la Pacha Mama, a la vida.

AGRADECIMENTOS: A la Dra. Bertha L. Salinas R., directora del Hospital Cemain, por su apoyo, a todo lo relacionado con la bioética.

\section{REFERÊNCIAS:}

[1] R. Ardila. Calidad de vida: una definición integradora. Revista Latinoamericana de Psicología, vol. 35, núm. 2, pp. 161-164 Fundación Universitaria Konrad Lorenz. Bogotá, Colombia. de: http://www.redalyc.org/pdf/805/80535203. Recuperado el 15 de Febrero de 2016

[2] M. Beuchot. La hermenéutica y el ser humano. México. Paidós. (2015).

[3] L. Boff. Del Iceberg al Arca de Noé. Cantabria. Sal Terrae. . (2003).

[4] A.E. De Bianchetti. ¿Qué es el agua? http://iadaweb.com.ar/eventos/anteriores/7 congresoarg2004/El\%20Uso $\% 20$ Agricola $\% 20 \mathrm{del} \% 20$ Agua/El $\% 20 \mathrm{U}$ so $\% 20$ Agricola $\% 20$ del $\% 20$ Agua $\% 20$ \%20Prof.Bianchetti.doc?. Recuperado el 27 de abril de 2016

[5] J.L. De la Cruz. A. Tello, E.L. Ortiz. Desarrollo urbano de la cuenca baja del río Pánuco: riesgo y vulnerabilidad. México. Universidad autónoma de Tamaulipas (2015). 